\title{
The impact of vitamin D in breast cancer: genomics, pathways, metabolism
}

\section{Carmen J. Narvaez ${ }^{1}$, Donald Matthews ${ }^{1,2}$, Erika LaPorta ${ }^{1,2}$, Katrina M. Simmons ${ }^{1,2}$, Sarah Beaudin ${ }^{1,2}$ and JoEllen Welsh ${ }^{1,3 *}$}

${ }^{1}$ Cancer Research Center, University at Albany, Rensselaer, NY, USA

${ }^{2}$ Department of Biomedical Sciences, University at Albany, Rensselaer, NY, USA

${ }^{3}$ Department of Environmental Health Sciences, University at Albany, Rensselaer, NY, USA

Edited by:

Carsten Carlberg, University of

Eastern Finland, Finland

Reviewed by:

Mieke Verstuyf, KU Leuven, Belgium

Moray J. Campbell, Roswell Park

Cancer Institute, USA

*Correspondence:

JoEllen Welsh, Cancer Research

Center, University at Albany, 1

Discovery Drive, Rensselaer,

NY 12144, USA

e-mail:jwelsh@albany.edu
Nuclear receptors exert profound effects on mammary gland physiology and have complex roles in the etiology of breast cancer. In addition to receptors for classic steroid hormones such as estrogen and progesterone, the nuclear vitamin D receptor (VDR) interacts with its ligand $1 \alpha, 25(\mathrm{OH})_{2} \mathrm{D}_{3}$ to modulate the normal mammary epithelial cell genome and subsequent phenotype. Observational studies suggest that vitamin $D$ deficiency is common in breast cancer patients and that low vitamin $D$ status enhances the risk for disease development or progression. Genomic profiling has characterized many $1 \alpha, 25(\mathrm{OH})_{2} \mathrm{D}_{3}$ responsive targets in normal mammary cells and in breast cancers, providing insight into the molecular actions of $1 \alpha, 25(\mathrm{OH})_{2} \mathrm{D}_{3}$ and the VDR in regulation of cell cycle, apoptosis, and differentiation. New areas of emphasis include regulation of tumor metabolism and innate immune responses. However, the role of VDR in individual cell types (i.e., epithelial, adipose, fibroblast, endothelial, immune) of normal and tumor tissues remains to be clarified. Furthermore, the mechanisms by which VDR integrates signaling between diverse cell types and controls soluble signals and paracrine pathways in the tissue/tumor microenvironment remain to be defined. Model systems of carcinogenesis have provided evidence that both VDR expression and $1 \alpha, 25(\mathrm{OH})_{2} \mathrm{D}_{3}$ actions change with transformation but clinical data regarding vitamin $D$ responsiveness of established tumors is limited and inconclusive. Because breast cancer is heterogeneous, analysis of VDR actions in specific molecular subtypes of the disease may help to clarify the conflicting data. The expanded use of genomic, proteomic and metabolomic approaches on a diverse array of in vitro and in vivo model systems is clearly warranted to comprehensively understand the network of vitamin $D$ regulated pathways in the context of breast cancer.

Keywords: $1 \alpha, 25(\mathrm{OH})_{2} \mathrm{D}_{3}$, vitamin $\mathrm{D}$, calcitriol, VDR, breast cancer, genomics

\section{INTRODUCTION TO BREAST CANCER}

In the United States in 2013, breast cancer was estimated to account for $29 \%$ of new cancer cases and $14 \%$ of cancer deaths in women, making it the most common cancer diagnosed and the second most common cause of cancer mortality in women. While standard tumor pathology focuses on the presence or absence of hormone (estrogen, progesterone) and growth factor (HER2) receptors, it is now clear that breast cancer is an extremely heterogeneous disease. Genomic profiling has identified several molecularly defined sub-types of breast cancer including Luminal A, Luminal B, Basal, HER2, and Claudin-low (Cancer Genome Atlas Network, 2012). The most frequently diagnosed sub-type is Luminal A (51\%), followed by Luminal B (29\%), Basal (17\%), HER2 (12.5\%), and Claudin-low (2\%). The importance of these molecular subtypes cannot be underestimated as they allow for prediction of therapeutic targets and they display distinct clinical courses (Caan et al., 2014). Women whose tumors fit the Luminal A profile have the best prognosis whereas those whose tumors have Luminal B or Basal profiles have poor prognosis. Although many trials have assessed the impact of nutrients, including vitamin D, on breast cancer risk and progression, few have been designed to stratify results by molecular sub-type. This review will highlight the cumulative data on vitamin $\mathrm{D}$ actions in breast cancer while emphasizing the gaps in knowledge regarding its effects on specific molecular subtypes.

\section{OBSERVATIONAL AND INTERVENTION STUDIES ON VITAMIN D AND BREAST CANCER}

Population studies on vitamin D in relation to chronic diseases such as breast cancer are complicated by difficulties in accurately assessing dietary sources (confounders include natural foods vs. fortified foods, supplement use, intake of $D_{2}$ vs. $D_{3}$, and calcium status) and in estimating the amount of vitamin $\mathrm{D}_{3}$ generated through sunlight exposure (confounders include lifestyle, latitude, pollution, sunscreen, skin pigmentation, and age). Thus, it is not surprising that studies designed to address the impact of vitamin D status on breast cancer have yielded mixed results. While much data is supportive that high vitamin D status as 
measured by serum 25-hydroxyvitamin $\mathrm{D}\left(25(\mathrm{OH}) \mathrm{D}_{3}\right)$ is associated with decreased risk of breast cancer (Bauer et al., 2013; Bilinski and Boyages, 2013; Wang et al., 2013; Kim et al., 2014), longer disease free survival and reduced mortality (Rose et al., 2013; Maalmi et al., 2014; Mohr et al., 2014), some large studies have failed to support these associations (Kuhn et al., 2013). With respect to endogenous synthesis of vitamin $\mathrm{D}_{3}$, small scale studies supported the concept that sunlight exposure is associated with reduced risk of breast cancer, however, the associations were dependent on region of residence and skin pigmentation (John et al., 1999, 2007). Larger international studies have consistently demonstrated significant inverse correlations between incident solar radiation and breast cancer rates (Edvardsen et al., 2011; Engel et al., 2011, 2014; Grant, 2013; van der Rhee et al., 2013).

Data from randomized controlled trials (RCTs) of vitamin D supplementation in relation to breast cancer development have been inconclusive, with only slight benefits of supplementation sometimes observed (Sperati et al., 2013; Redaniel et al., 2014). The large (>30,000 women) Women's Health Initiative (WHI) trial assessed the impact of supplementation with both calcium and vitamin $\mathrm{D}$ on multiple health outcomes including cancer. However, the data from this trial was confounded by the low dose of vitamin D (400 IU/day), coadministration of calcium supplements, poor compliance, extensive pre-trial supplement use in the study population and the freedom for trial participants to take additional personal supplements of up to $1000 \mathrm{IU}$ vitamin D per day. Thus it was not surprising that initial data from the WHI trial indicated no significant effects of vitamin D plus calcium supplementation on breast cancer. Subgroup and follow-up analyses of trial participants have yielded mixed results. One report indicated that higher intake of vitamin D was moderately associated with a lower risk of pre- but not post- menopausal breast cancer (Lin et al., 2007). In another sub-group analysis (including only women who were not taking personal calcium or vitamin D supplements at randomization), risk of invasive breast cancers was decreased in women supplemented with calcium and vitamin D (Bolland et al., 2011). The most recent analysis of all WHI diet study participants (assessed 5 years after intervention ended) indicated a reduced incidence of in situ breast cancers in the calcium and vitamin D cohort but also suggested that women with the highest vitamin $\mathrm{D}$ intakes may have an increased risk of invasive breast cancer (Cauley et al., 2013). Further sub-group analysis based on menopausal status or molecular subtype may shed light on these discrepancies. Regardless, these inconsistent data emphasize the continued need for rigorous, well-designed RCTs to specifically assess the impact of vitamin D supplementation on breast cancer development. Of note, the ongoing VITAL trial of 20,000 men and women taking daily supplements of $2000 \mathrm{IU}$ vitamin $\mathrm{D}_{3}$ (http://www.vitalstudy.org/) is monitoring breast cancer as one outcome.

As discussed above, genomic studies have demonstrated that breast cancers are heterogeneous and that different subtypes exhibit distinct patterns of disease progression. It is likely that VDR expression or function and thus sensitivity to changes in vitamin $\mathrm{D}$ status may be subtype specific, yet this has not rigorously been examined. The limited epidemiologic data that has been stratified by subtype is mixed - one study reported that the relationship between serum $25(\mathrm{OH}) \mathrm{D}$ and reduced risk of breast cancer was strongest for high grade, ER negative or triple negative cancers (Yao and Ambrosone, 2013) whereas another found that low serum $25(\mathrm{OH}) \mathrm{D}$ was associated with poor prognosis only in women with the luminal subtype of breast cancer (Kim et al., 2011). It should be noted that while vitamin D deficiency is common in all breast cancer patient populations, it is particularly prevalent in those with triple negative/basal-like tumors, the most aggressive form of the disease (Rainville et al., 2009; Peppone et al., 2012; Yao and Ambrosone, 2013). Even without rigorous "proof" of a beneficial effect of supplemental vitamin D on breast cancer, correction of vitamin D deficiency in women at risk for, or living with, breast cancer should be standard practice.

\section{VITAMIN D PATHWAY EXPRESSION IN NORMAL MAMMARY CELLS AND BREAST CANCER PREVENTION}

The VDR is present in rat, mouse and human mammary gland and its expression is highest during puberty, pregnancy and lactation (Berger et al., 1987; Zinser et al., 2002). In actively growing murine mammary ducts, VDR expression is high in the ductal epithelium and low in the proliferating terminal end buds. Consistent with this murine data, high content immunohistochemistry of normal human breast epithelium demonstrated that VDR positive cells are exclusively found in the luminal (differentiated) cell layer and do not co-localize with proliferating Ki67 positive cells (Santagata et al., 2014). VDR has also been identified in the stromal compartment including the mammary fibroblasts and adipocytes (Ching et al., 2011; Campos et al., 2013; Knower et al., 2013), highlighting the complexity of $1,25(\mathrm{OH})_{2} \mathrm{D}_{3}$ signaling in the breast tissue environment.

In addition to VDR, the $25(\mathrm{OH}) \mathrm{D}$ activating enzyme CYP27B1 is expressed in murine and human mammary tissue (Zinser and Welsh, 2004a; Townsend et al., 2005; Kemmis et al., 2006; Peng et al., 2009), suggesting that systemic 25(OH)D delivered to the mammary gland can be converted to the biologically active VDR ligand $1,25(\mathrm{OH})_{2} \mathrm{D}_{3}$. In vitro studies confirm that incubation of mammary epithelial cells with physiological (nanomolar) concentrations of $25(\mathrm{OH}) \mathrm{D}$ leads to temporal increases in $1,25(\mathrm{OH})_{2} \mathrm{D}_{3}$ detected in tissue culture media (Kemmis et al., 2006). Although there is still uncertainty regarding how $25(\mathrm{OH}) \mathrm{D}$, which circulates tightly bound to the vitamin $\mathrm{D}$ binding protein (DBP), is internalized by non-renal cells, the presence of megalin and cubilin (Rowling et al., 2006) indicates that these accessory proteins could mediate uptake of $25(\mathrm{OH}) \mathrm{D}$ DBP complexes in mammary gland as has been demonstrated for renal cells(Willnow and Nykjaer, 2002). Indeed, in vitro studies demonstrate that normal breast epithelial cells and some breast cancer cells internalize $25(\mathrm{OH}) \mathrm{D}$ via megalin-mediated endocytosis (Rowling et al., 2006), however, the function of this uptake pathway in intact mammary gland has yet to be confirmed. CYP27B1 is also expressed in mammary adipocytes, which too are capable of converting $25(\mathrm{OH}) \mathrm{D}$ to $1,25(\mathrm{OH})_{2} \mathrm{D}_{3}$ in organoid culture (Ching et al., 2011). Collectively, these studies provide a biological link between vitamin D status [i.e., serum 25(OH)D] and breast cancer risk that is observed at the population level.

The functions of CYP27B1 and VDR in prevention of breast cancer are supported by data from animal models. In vivo, both 
high dietary vitamin D (Jacobson et al., 1989) and treatment with synthetic VDR agonists (Hussain et al., 2003) inhibit the development of carcinogen induced mammary tumors. Furthermore, VDR ablation enhances the development of hyperplasias and hormone independent mammary tumors after DMBA administration, and VDR haploinsufficiency sensitizes the mammary gland to tumorigenesis driven by the neu oncogene (Zinser et al., 2002; Zinser and Welsh, 2004b). In organ culture models, VDR agonists such as $25(\mathrm{OH}) \mathrm{D}_{3}$ and $1 \alpha, 25(\mathrm{OH})_{2} \mathrm{D}_{3}$ reduce the incidence of DMBA induced pre-neoplastic lesions (Mehta et al., 1997; Peng et al., 2009) suggesting direct anti-cancer effects of these metabolites on mammary tissue. Collectively, these data support the concept that systemic $25(\mathrm{OH}) \mathrm{D}$ delivered to mammary gland is converted to $1,25(\mathrm{OH})_{2} \mathrm{D}_{3}$ which activates VDR to protect against carcinogenesis.

Despite these consistent data, the precise mechanisms by which vitamin $\mathrm{D}$ inhibits cancer development have yet to be discerned. Both $25(\mathrm{OH}) \mathrm{D}_{3}$ and $1 \alpha, 25(\mathrm{OH})_{2} \mathrm{D}_{3}$ exert profound effects on non-tumorigenic VDR positive mammary epithelial cells including inhibition of hormone stimulated growth and branching morphogenesis and induction of differentiation biomarkers such as E-cadherin. VDR and CYP27B1 expression in mammary adipocytes also contribute to the anti-cancer effects in the whole tissue, since in response to $25(\mathrm{OH}) \mathrm{D}$ adipocytes secrete diffusible signals that inhibit morphogenesis of the adjacent ductal epithelium (Ching et al., 2011). Other potential mechanisms for breast cancer prevention by vitamin $\mathrm{D}$ include reduction in DNA damage (possibly via up-regulation of p53 signaling), suppression of oxidative stress and inhibition of angiogenesis, many of which have been demonstrated in tissues or cell types other than mammary gland (Kallay et al., 2002; Peng et al., 2010; Bruce et al., 2011; Hopkins et al., 2011; Krishnan and Feldman, 2011; Bikle, 2012; Dogan et al., 2012; Gordon-Thomson et al., 2012; Ting et al., 2012; Alvarez et al., 2014; Nakai et al., 2014; Sun et al., 2014; Uberti et al., 2014; Zhong et al., 2014). In addition, recent data from our group and others implicate alteration of cellular energy metabolism and innate immune responses in the anti-cancer effects of vitamin D signaling on non-tumorigenic mammary epithelial cells as described below.

Although initially recognized by Otto Warburg more than 50 years ago (Warburg, 1956), attention has recently been re-focused on the role of cellular energy metabolism as a critical component of tumor initiation and progression. It is now recognized that many cancer cells preferentially rely on glycolysis to generate energy and macromolecules that are essential for rapid proliferation, even in the presence of normoxia. The metabolic switch (the "Warburg effect") from oxidative phosphorylation to aerobic glycolysis is triggered in normal cells by activation of oncogenes and/or loss of tumor suppressors which, in part, target glucose and glutamine metabolism. The best characterized oncogenic driver of the metabolic switch, myc, induces a cohort of genes that promote glycolysis and alter glutamine flux. Conversely, tumor suppressors such as p53 normally suppress glycolysis and enhance flux through the tricarboxylic acid (TCA) cycle and oxidative phosphorylation. p53 also increases intracellular glutamate which is shunted toward glutathione synthesis, enhancing antioxidant defense against reactive oxygen species. Recent studies support the concept that vitamin D might target energy utilization pathways in non-tumorigenic breast cells to prevent carcinogenesis. The regulation of cellular glucose metabolism by $1,25(\mathrm{OH})_{2} \mathrm{D}_{3}$ has been studied (Zheng et al., 2013) in pre-malignant mammary cells (MCF10A cells) compared to their ras transformed malignant derivatives (MCF10A-ras cells). In this model, 4-day $1,25(\mathrm{OH})_{2} \mathrm{D}_{3}$ treatment reduced flux of glucose through glycolysis in both MCF10A and MCF10A-ras cells, with a more pronounced effect in the transformed cells. $1,25(\mathrm{OH})_{2} \mathrm{D}_{3}$ also reduced the flux of glucose to acetyl-coA and oxaloacetate in both cell lines, suggesting a reduction in TCA cycle activity. The predicted consequences of these $1,25(\mathrm{OH})_{2} \mathrm{D}_{3}$ inducedchanges would be limitation in the availability of TCA-derived precursors for macromolecule synthesis, coincident with reduction in proliferation.

In microarray profiling of non-tumorigenic mammary epithelial cells (hTERT-HME1) cells, we identified SLC1A1, which encodes a plasma membrane glutamate transporter, and GLUL, which encodes glutamine synthetase (GS) as novel $1,25(\mathrm{OH})_{2} \mathrm{D}_{3}$ targets. We validated that $1,25(\mathrm{OH})_{2} \mathrm{D}_{3}$ increases SLC1A1 mRNA (>10-fold) and decreases GLUL mRNA (>4-fold) in these cells, and also demonstrated decreased expression of the cognate proteins GS and SLC1A1 by western blotting. These changes in metabolic gene/protein expression correlated with accumulation of glutathione and changes in respiratory capacity in $1,25(\mathrm{OH})_{2} \mathrm{D}_{3}$ treated cells. Furthermore, $1,25(\mathrm{OH})_{2} \mathrm{D}_{3}$ pretreatment hindered growth of hTERT-HME1 cells in glutamine-starved media and exogenous glutamine partially rescued 1,25D-mediated growth arrest. These findings are intriguing because: (a) glutamate uptake and glutamate transporters are enhanced during differentiation and deregulated in cancer cells; (b) SLC1A1 null mice exhibit GSH deficiency and high oxidative stress; (c) GS enzymatic activity is necessary for adaption of mammary cells to glutamine depletion; and (d) data compiled from The Human Protein Atlas indicates that SLC1A1 is reduced and GLUL is increased in human breast cancers relative to normal tissue. Thus, we propose that $1,25(\mathrm{OH})_{2} \mathrm{D}_{3}$ regulation of SLC1A1 and GLUL synergizes with p53 to alter metabolic flux, prevent the myc-driven metabolic switch and induce quiescence in normal mammary epithelial cells. Collectively, these emerging data demonstrating regulation of amino acid and glucose metabolism (Zheng et al., 2013) in mammary epithelial cells by $1,25(\mathrm{OH})_{2} \mathrm{D}_{3}$ provides another mechanism by which vitamin $\mathrm{D}$ may act to prevent carcinogenesis in normal breast tissue. These changes may be complemented by alterations in lipid and energy metabolism in adjacent stromal adipocytes by $1,25(\mathrm{OH})_{2} \mathrm{D}_{3}$ (Welsh et al., 2011; Narvaez et al., 2013).

Another emerging area in cancer prevention by vitamin D involves suppression of inflammation. We identified CD14, a component of the innate immune system, as the second most highly upregulated gene (second only to CYP24A1) in $1,25(\mathrm{OH})_{2} \mathrm{D}_{3}$ treated hTERT-HME1 cells. CD14 is a known VDR target in macrophages and other immune cells, but its regulation by $1,25(\mathrm{OH})_{2} \mathrm{D}_{3}$ in mammary cells has not been well studied. In contrast to macrophages where $1,25(\mathrm{OH})_{2} \mathrm{D}_{3}$ induces membrane bound $\mathrm{CD} 14$, both $1,25(\mathrm{OH})_{2} \mathrm{D}_{3}$ and $25(\mathrm{OH}) \mathrm{D}_{3}$ induce the secretion of large quantities of soluble CD14 (sCD14) from 
mammary epithelial cells. As a pattern recognition receptor, sCD14 binds lipopolysaccharide and contributes to protection against mastitis in mammary tissue (Lee et al., 2003; Zheng et al., 2006; Wall et al., 2009). The soluble form of CD14 is also secreted into human milk where it contributes to protection of the neonatal gut from infections (Vidal and Donnet-Hughes, 2008). However, even in the absence of infection or lactation, CD14 and other genes involved in innate immunity are highly induced during regression of the mammary gland after weaning (Stein et al., 2004). The role of CD14 during this period of glandular remodeling may be the recognition and disposal of apoptotic cells (Heidenreich, 1999; Devitt et al., 2004; Tennant et al., 2013). We speculate that vitamin D induction of soluble CD14 in mammary tissue inhibits activation of tissue resident macrophages, suppressing inflammation which is known to drive cancer development and progression(McMahon et al., 2011; Simpson and Brown, 2013). However, it remains to be determined whether vitamin D status regulates any of these proposed functions of CD14 in mammary tissue in vivo. One caveat to future experimentation on vitamin D regulation of CD14 is the apparent discordance between the human and murine genomes. $1,25(\mathrm{OH})_{2} \mathrm{D}_{3}$ does not induce CD14 in the murine mammary epithelial cell line HC11 and CD14 gene expression is not altered in the mammary gland of VDRKO mice (Welsh, unpublished).

\section{VITAMIN D PATHWAY EXPRESSION IN ESTABLISHED BREAST CANCER}

Over 30 years ago, the recognition that VDR expression was retained in breast cancers prompted extensive studies to determine whether targeting VDR in tumors would provide therapeutic benefit. VDR expression is retained in the majority of rodent breast tumors, human breast cancers and established breast cancer cell lines (Colston et al., 1986; Buras et al., 1994; Zinser and Welsh, 2004b). In a study of 136 patients with primary breast cancer, it was found that women with VDR negative tumors relapsed significantly earlier than women with VDR positive tumors (Berger et al., 1991). Of note, some data suggests that receptor protein expression declines in highly aggressive tumors (Lopes et al., 2010). We reviewed the frequency of genomic VDR changes in human breast cancers using datasets publically available on The Cancer Genome Atlas (https://tcga-data.nci.nih.gov/ tcga/) which annotates mutations, amplifications, deletions and mRNA expression profiles in human tumors (Table 1). Analysis of the TCGA invasive breast cancer dataset (Cancer Genome Atlas Network, 2012) of over 450 breast tumors suggests that alterations in the VDR gene are rare in human breast cancer. As shown in Table 1, only $5 \%$ of human breast tumors exhibited any alteration in VDR sequence or expression. However, when the VDR gene was altered, the most common change was a reduction in mRNA expression (deletions and mutations did not occur). With respect to VDR expression in specific molecular sub-types, the Luminal B subtype had the highest frequency of VDR alterations with $10.5 \%$ of tumors displaying reduced VDR mRNA expression compared to $0-3 \%$ for Luminal A, Basal, HER2, or ClaudinLow subtypes. These results showing retention of VDR in the majority of human breast tumors are consistent with the data of Santagata et al. (2014) who used a multiplex immunohistochemical approach to map receptor proteins at the single cell level and confirmed that the majority of human breast tumors are VDR positive. Interestingly, this study also demonstrated that breast tumors with the highest expression of VDR, ER, and Androgen Receptor (AR) had the best prognosis. The retention of VDR in tumors may indicate that its function has been somehow abrogated, either by altered function of the VDR despite mutation (i.e., alteration of transcriptional co-regulators), reduced ligand availability (i.e., loss of CYP27B1 and/or gain of CYP24A1), or mutation/deregulation of critical anti-cancer VDR target genes.

Despite these data, in vitro studies have demonstrated that specific oncogenes can deregulate VDR expression. For instance, comparison of VDR expression in a series of isogenic,

Table 1 | Frequency of genomic alterations in VDR and CYP24A1 derived from The Cancer Genome Atlas dataset of human breast tumors.

\begin{tabular}{|c|c|c|c|c|c|c|}
\hline & All tumors $(n=463)$ & Lum A ( $n=235)$ & Lum B (n=133) & Basal $(n=81)$ & HER2 $(n=58)$ & CLN Lo $(n=8)$ \\
\hline \multicolumn{7}{|l|}{ VDR } \\
\hline$\%$ Alterations & 5.2 & 3.4 & 11.3 & 4.9 & 3.4 & 0 \\
\hline Deletions & 0 & 0 & 0 & 0 & 0 & 0 \\
\hline Mutations & 0 & 0 & 0 & 0 & 0 & 0 \\
\hline \multicolumn{7}{|l|}{ CYP24A1 } \\
\hline$\%$ Alterations & 9.7 & 9.8 & 11.3 & 7.4 & 10.3 & 12.5 \\
\hline Amplifications & 5.6 & 4.7 & 9.8 & 1.2 & 10.3 & 0 \\
\hline Deletions & 0.2 & 0.2 & 0 & 0 & 0 & 0 \\
\hline Mutations & 0.4 & 0.2 & 0.8 & 0 & 0 & 0 \\
\hline
\end{tabular}

The data was calculated with the publically available breast invasive carcinoma dataset (Cancer Genome Atlas Network, 2012) at https://tcga-data.nci.nih.gov/tcga/as. Numbers indicate the percentage of the indicated genomic alterations observed in the total number of tumors analyzed within each group (shown in parentheses). LumA, Luminal A; LumB, Luminal B; CLN Lo, Claudin Low. 
progressively transformed human mammary epithelial (HME) cell lines indicated that VDR expression and function was reduced more than 70\% in HME cells expressing SV40 and/or RAS compared to the non-transformed HME cells from which they were derived (Kemmis and Welsh, 2008). Likewise, SV40 and RAS have been shown to reduce VDR activity in other breast cancer cell model systems (Agadir et al., 1999; Escaleira and Brentani, 1999). Transcriptional repressors linked to the epithelial mesenchymal transition such as SNAIL and SLUG have also been shown to down-regulate VDR (Mittal et al., 2008; Larriba et al., 2010). Thus, it is clear that there are distinct mechanisms targeting both the VDR gene itself and its protein product. Data on receptor expression derived from whole tumors may be somewhat misleading since cancer progression is driven by genetic instability and outgrowth of cells with advantageous mutations, such as activation of oncogenes. These studies indicate that abrogated expression and/or function of VDR may be limited to certain subsets of cells within individual tumors that have sustained specific molecular genetic alterations.

In addition to genetic alterations and effects of oncogenes, VDR abundance is affected by many physiological agents, including $1,25(\mathrm{OH})_{2} \mathrm{D}_{3}$ itself, estrogens, retinoids and growth factors. Thus, cell sensitivity to $1,25(\mathrm{OH})_{2} \mathrm{D}_{3}$ may also reflect the activity of other hormone signaling pathways through their impact on VDR expression. In breast cancer, the regulation of VDR expression and activity by estrogens is likely to be clinically significant. ER positive cells tend to express higher levels of VDR than ER negative cells (Buras et al., 1994) and in vitro studies have demonstrated that estrogen up-regulates whereas anti-estrogens down regulate VDR in ER positive breast cancer cells (Nolan et al., 1998; Byrne et al., 2000). Further studies are therefore warranted to determine the degree to which estrogen status influences VDR abundance in different $1,25(\mathrm{OH})_{2} \mathrm{D}_{3}$ target tissues (i.e., breast, bone, uterus), and whether common therapeutic synthetic or natural estrogens act as estrogen agonists or antagonists in regulation of VDR expression. Consistent with this concept, some data suggests that phytoestrogens such as resveratrol and genestein can alter VDR expression and $1,25(\mathrm{OH})_{2} \mathrm{D}_{3}$ sensitivity in cancer cells in vitro (Wietzke and Welsh, 2003; Gilad et al., 2006).

Other tumor-associated changes that can lead to $1,25(\mathrm{OH})_{2} \mathrm{D}_{3}$ resistance in VDR positive tumors include disruption of VDR transcriptional activation and enhanced catabolism of its ligand. Data from breast, bladder and prostate cancer suggests that alterations in transcriptional co-regulators can abrogate signaling by the $1,25(\mathrm{OH})_{2} \mathrm{D}_{3}$-VDR complex (Malinen et al., 2008; Abedin et al., 2009). Enhanced mammary cell catabolism of $1,25(\mathrm{OH})_{2} \mathrm{D}_{3}$ would also be predicted to limit the formation of active VDR complexes. Indeed, amplification of the CYP24A1 gene was reported in human breast tumors (Albertson et al., 2000) and analysis of the datasets from The Cancer Genome Atlas confirms that a subset of human breast cancers (10-13\%) exhibit alterations in the CYP24 gene, with the most frequent changes being amplifications and upregulation at the mRNA level (Table 1). There is no obvious subtype specificity to CYP24A1 changes, although amplifications were somewhat more frequent in Luminal B and HER2 subtypes whereas increased mRNA levels were more common in Basal and Claudin-low tumors. These data are consistent with analysis of tumor samples which demonstrated higher CYP24A1 protein expression in breast tumors compared to adjacent normal tissue (Townsend et al., 2005; Lopes et al., 2010). Furthermore, splicing variants of CYP24A1 have been reported in breast cancer cell lines (Scheible et al., 2014), suggesting that distinct forms of the enzyme with altered properties may be expressed in tumors. The significance of the CYP24A1 deregulation with respect to overall catabolism of vitamin $\mathrm{D}$ metabolites in situ has yet to be ascertained.

Given that normal mammary cells utilize $25(\mathrm{OH}) \mathrm{D}_{3}$ as substrate for local tissue generation of $1,25(\mathrm{OH})_{2} \mathrm{D}_{3}$, imbalanced expression of either CYP24A1 or CYP27B1 favoring catabolism could theoretically contribute to escape of developing tumor cells from anti-cancer VDR signaling. In the HME cell model, oncogenic transformation was associated with reduced CYP27B1 expression and activity [as measured by $1,25(\mathrm{OH})_{2} \mathrm{D}_{3}$ synthesis]. The reductions in CYP27B1 in the oncogene-transformed HME cells were of sufficient magnitude to reduce cellular sensitivity to growth inhibition by $25(\mathrm{OH}) \mathrm{D}_{3}$ approximately 100 -fold (Kemmis and Welsh, 2008). However, clinical data on CYP27B1 expression in breast cancer is inconsistent (Segersten et al., 2005; Townsend et al., 2005; de Lyra et al., 2006; McCarthy et al., 2009; Lopes et al., 2010) and less than $2 \%$ of breast cancers annotated in The Cancer Genome Atlas datasets exhibit genomic alterations in CYP27B1. However, altered splice variants of CYP27B1 have been detected in breast cancer cells (Cordes et al., 2007; Fischer et al., 2007) suggesting the possibility that forms of the CYP27B1 enzyme with altered function could be expressed in breast tumors.

\section{ACTIONS OF VDR AGONISTS ON BREAST CANCER CELLS AND TUMORS}

Numerous studies have profiled the cellular and molecular effects of $1,25(\mathrm{OH})_{2} \mathrm{D}_{3}$ on VDR positive breast cancer cells. Furthermore, a large number of structural analogs of vitamin $\mathrm{D}$ developed by pharmaceutical companies and academic researchers have been used to probe the mechanisms of vitamin D mediated growth inhibition. In general, the effects of VDR agonists on breast cancer cells include modulation of key cell cycle regulators to induce $\mathrm{G} 0 / \mathrm{G} 1$, induction of differentiation markers, and/or activation of cell death (via apoptosis or autophagy). Notably, studies with cells derived from VDRKO mice has definitely established that the nuclear VDR is required for the anti-proliferative and pro-apoptotic effects of $1,25(\mathrm{OH})_{2} \mathrm{D}_{3}$ in transformed mammary cells in vitro (Zinser et al., 2003; Valrance et al., 2007). In addition to regulation of cell growth and survival, studies in ER negative breast cancer cells, representative of late stage disease, have provided evidence that $1,25(\mathrm{OH})_{2} \mathrm{D}_{3}$ alters genomic stability, inhibits angiogenesis and reduces invasion and metastasis. For instance, $1,25(\mathrm{OH})_{2} \mathrm{D}_{3}$ interacts with the $53 \mathrm{BP} 1$ protein to eliminate invasive breast cancer cells lacking BRCA1 (Grotsky et al., 2013). 1,25(OH) ${ }_{2} \mathrm{D}_{3}$ and analogs inhibit invasion as measured by the Boyden chamber assay (Flanagan et al., 2003) likely through suppression of extracellular proteases (MMP-9, urokinase-type plasminogen activator, tissue type plasminogen activator), protease inhibitors and adhesion molecules. Comparative studies of breast tumors and normal adjacent breast 
tissue in an explant system confirmed that malignant tissue is responsive to $1,25(\mathrm{OH})_{2} \mathrm{D}_{3}$ but that the magnitude of the response is highly disparate between individual patients (Suetani et al., 2012; Milani et al., 2013). Furthermore, tumor tissue was far less sensitive to $25(\mathrm{OH}) \mathrm{D}_{3}$ than $1,25(\mathrm{OH})_{2} \mathrm{D}_{3}$ (Suetani et al., 2012).

Animal models of established breast cancer have demonstrated that VDR agonists can reduce tumor growth (and in some cases trigger tumor regression) with minimal effects on calcemia [the most common and dangerous side effect of $1,25(\mathrm{OH})_{2} \mathrm{D}_{3}$ therapy]. In experimental metastasis paradigms, the vitamin $\mathrm{D}$ analog EB1089 inhibited secondary tumors, blocked skeletal metastases and improved survival (El Abdaimi et al., 2000; Flanagan et al., 2003). More recently, dietary modifications have been shown to alter breast tumor growth and progression. Increasing dietary vitamin $\mathrm{D}_{3}$ from $1000 \mathrm{IU} / \mathrm{kg}$ diet (rodent standard) to $5000 \mathrm{IU} / \mathrm{kg}$ diet significantly reduced growth of established MCF7 xenografts, with equivalent potency to $1,25(\mathrm{OH})_{2} \mathrm{D}_{3}$ (Swami et al., 2012). In another study, vitamin D deficiency sufficient to enhance bone turnover promoted the skeletal growth of breast cancer metastases (Ooi et al., 2010). For further details on these and other in vivo studies, several recent comprehensive reviews on vitamin D and breast cancer are available (Krishnan and Feldman, 2011; Lopes et al., 2012; Welsh, 2012).

\section{GENOMIC PROFILING OF VDR AGONISTS IN BREAST CANCER MODEL SYSTEMS}

Screening for molecular changes induced by $1,25(\mathrm{OH})_{2} \mathrm{D}_{3}$ or vitamin $\mathrm{D}$ analogs in various breast cancer cells has identified scores of VDR regulated genes and proteins, indicating a broad range of downstream targets. Here we will focus on the few comprehensive genomic studies that have allowed for identification of vitamin $\mathrm{D}$ responsive pathways in breast cancer (Lee et al., 2006; Campos et al., 2013; Milani et al., 2013; Laporta and Welsh, 2013). In the first study of vitamin D mediated genomic changes in breast cancer, Feldman's groups used early generation arrays to compare gene expression in ER positive MCF-7 cells and ER negative MDA-MB-231 cells treated with $100 \mathrm{nM} 1,25(\mathrm{OH})_{2} \mathrm{D}_{3}$ (Swami et al., 2003). Due to the limited nature of these arrays, which comprised 2000 cancer related genes, direct comparisons with whole genome profiling arrays isn't appropriate. However, comparisons between the two cell lines is of interest. Using a 2-fold cutoff, 62 genes (47 up/15 down) in MCF-7 cells and 20 genes in MDA-MB-231 cells (10 up/10 down) were significantly altered by $24 \mathrm{~h}$ treatment with $100 \mathrm{nM} 1,25(\mathrm{OH})_{2} \mathrm{D}_{3}$, with only seven genes commonly altered in both cell lines. The larger number of regulated genes in MCF-7 cells was not surprising as CYP24A1 induction was 10-fold higher in MCF-7 cells (52-fold) than in MDA-MB-231 cells (5.5-fold). Other highly regulated genes in MCF-7 cells treated with $1,25(\mathrm{OH})_{2} \mathrm{D}_{3}$ for $24 \mathrm{~h}$ included RBL2, CTNNA1, RAD23B, NCOA4, BMP5 and IFNG (up) and CEACAM1, CDH6, IL13, IL1R2 and ESR (down). In MDA-MB231 cells, highly modulated genes at $24 \mathrm{~h}$ included CASP4, NF1B, ITGAV, TXNRD1 and TGFB2 (up) and ANGPT1, four MMPs $(12,10,7,1)$ and PRKD1 (down). Thus, in MCF-7 cells, many of the $1,25(\mathrm{OH})_{2} \mathrm{D}_{3}$ regulated genes were involved in growth factor signaling, cell cycle, apoptosis and immune responses, whereas in MDA-MB-231 cells genes related to disease progression (i.e., invasion and angiogenesis) were altered.

Since the availability of whole genome arrays, four studies (Lee et al., 2006; Campos et al., 2013; Milani et al., 2013; Laporta and Welsh, 2013) on the effects of VDR agonists [three with $1,25(\mathrm{OH})_{2} \mathrm{D}_{3}$, one with a synthetic VDR agonist] in breast cancer model systems have reported although only one of these datasets (Milani et al., 2013, accession \#GSE27220) is publically available on the Gene Expression Omnibus website (http://www. ncbi.nlm.nih.gov/geo/). Lee et al. (2006) compared the effects of $1 \mathrm{nM}$ RO3582, a Gemini $1,25(\mathrm{OH})_{2} \mathrm{D}_{3}$ analog, on pre-malignant (MCF10AT1) and malignant (MCF10CA1a) breast cancer cells and identified distinct gene expression profiles for each cell line. Similar to the comparison of MCF-7 and MDA-MB-231 cells (Swami et al., 2003), more significant changes in gene expression were observed in the less malignant MCF10AT1 cells than in the invasive MCF10CA1a cells (391 vs. 156, respectively, $12 \mathrm{~h}$ treatment; 2-fold cutoff). Despite the reduced sensitivity in the more aggressive cells, the overlap in target genes was considerable (about 55\% of the genes altered in MCF10AT1 cells were similarly altered in the MCF10CA1a cells); the complete gene lists are available as supplemental data.

Using an approach designed to more accurately represent the tumor microenvironment in situ, tumor slices from postmenopausal breast cancer patients with stage I, II, or III breast cancer were cultured with 0.5 or $100 \mathrm{nM} 1,25(\mathrm{OH})_{2} \mathrm{D}_{3}$ for $24 \mathrm{~h}$ (Milani et al., 2013). This study identified nine genes that were significantly altered within $24 \mathrm{~h}$ of exposure to $0.5 \mathrm{nM}$ $1,25(\mathrm{OH})_{2} \mathrm{D}_{3}$, a concentration that is physiologically achievable in patients. Of these, CYP24A1 was induced over 7-fold and was validated in another set of tumor samples, clearly indicating activation of VDR signaling. Gene set enrichment analysis (GSEA) indicated a trend toward the enrichment of genes sharing DR3 binding sites, a consensus motif for VDR. Other genes identified in response to $0.5 \mathrm{nM} 1,25(\mathrm{OH})_{2} \mathrm{D}_{3}$ included DPP4, CYP26B1, SPIN3, KCKN3, EFTUD1, TKTL1, and CA2 (up-regulated) and FCGR2C and SAMSN1 (down-regulated). At $100 \mathrm{nM} 1,25(\mathrm{OH})_{2} \mathrm{D}_{3}, 30$ genes (28 up/2 down) were significantly regulated by $1,25(\mathrm{OH})_{2} \mathrm{D}_{3}$. In addition to those listed above, genes up-regulated by 3 -fold or more included IL1RL1, CILP, PI15, TMEM37, and SHE. The two top down-regulated genes (2-fold or more) were P2RY1 and BCOR. Interestingly, CD14 and SLC1A1, two $1,25(\mathrm{OH})_{2} \mathrm{D}_{3}$ regulated genes we identified in the genomic profiles of normal mammary epithelial cells discussed above, were also induced by $1,25(\mathrm{OH})_{2} \mathrm{D}_{3}$ in the breast cancer slice model. The significance of this study is that it demonstrated for the first time that $1,25(\mathrm{OH})_{2} \mathrm{D}_{3}$ could induce genomic changes in intact breast tumor tissue, indicating the functionality of the VDR. Although patient-to-patient variability was considerable, a core set of $1,25(\mathrm{OH})_{2} \mathrm{D}_{3}$ modulated genes was identified that may represent biomarkers of vitamin $\mathrm{D}$ action for future studies.

A fourth genomic study was recently conducted in a mouse mammary tumor model of triple negative breast cancer (Laporta and Welsh, 2013). Cells derived from DMBA induced tumors generated in wildtype (WT) and VDRKO mice were studied after $24 \mathrm{~h}$ treatment with $100 \mathrm{nM} 1,25(\mathrm{OH})_{2} \mathrm{D}_{3}$. A unique feature 
of this study was the inclusion of VDRKO cells in which the growth inhibitory effects of $1,25(\mathrm{OH})_{2} \mathrm{D}_{3}$ were restored via stable expression of human VDR (KO ${ }^{\text {hVDR }}$ cells). Genomic profiling demonstrated that $1,25(\mathrm{OH})_{2} \mathrm{D}_{3}$ failed to alter gene expression in VDRKO cells whereas major changes were observed in cells derived from WT mice (WT145 cells) and in KO ${ }^{\text {hVDR }}$ cells. With a 2-fold cutoff, 117 transcripts in WT145 cells and 197 transcripts in the $\mathrm{KO}^{\text {hVDR }}$ clones were significantly altered by $1,25(\mathrm{OH})_{2} \mathrm{D}_{3}$ with 35 genes found to be commonly regulated in all VDRpositive cell lines (the complete list of genes is included in the manuscript). In addition to Cyp24a1, seven genes were validated as $1,25(\mathrm{OH})_{2} \mathrm{D}_{3}$ responsive and VDR dependent in this system: Cib2, Prelp, Enpp1, Plau, Hbegf, Postn, and Has2. The last four of these, whose expression was markedly down regulated by $1,25(\mathrm{OH})_{2} \mathrm{D}_{3}$, are known to drive breast cancer invasion and metastasis. These data support a model whereby $1,25(\mathrm{OH})_{2} \mathrm{D}_{3}$ coordinately suppresses multiple proteins that are required for survival of triple-negative/basal-like breast cancer cells.

In summary, while CY24A1 is commonly identified in microarray studies as the most highly upregulated gene in $1,25(\mathrm{OH}) \mathrm{D}$ treated cells, other target genes vary greatly depending on the model system. Integration of the existing genomic datasets generated in various mammary cell models with other normal and transformed array profiles and ChIP-Seq studies will assist in identifying common and tissue/cell specific genesets regulated by the $1,25(\mathrm{OH})_{2} \mathrm{D}_{3}$-VDR complex. In addition, the ENCODE project (http://genome.ucsc.edu/ENCODE/cellTypes. html) includes several breast cancer cell lines (MCF-7, MDA-MB231, T47-D) which may provide relevant genomic information on nuclear receptor signaling The continued use of complex models such as tumor explants for vitamin D studies is desirable given the expression of VDR in most cell types and the critical interactions between tumor cells and their stromal microenvironment.

\section{CONCLUSIONS}

Although meta-analyses of population studies demonstrate an inverse relationship between vitamin $\mathrm{D}$ status and breast cancer risk, questions remain regarding mechanisms, tissue specificity, and optimal intakes of vitamin $\mathrm{D}_{3}$ for potential benefits on cancer. In 2010, the Institute of Medicine recommended an increase in the adult intake of vitamin $\mathrm{D}_{3}$ (from 200 to 600 IU per day) based on its role in bone health, but concluded that current data is insufficient to support recommendations with respect to cancer prevention. Comprehensive genomic, metabolomic and proteomic profiling approaches combined with mechanistic studies remain highly valuable for identification of relevant biomarkers of tissue vitamin $\mathrm{D}$ action that are needed for translational investigations (i.e., supplementation trials).

\section{FUTURE VIEW}

Despite the extensive effort to understand the relationship between vitamin $\mathrm{D}$ and breast cancer, many issues remain unresolved. Much of the work conducted in cell systems or animal models is consistent, but epidemiological data is somewhat mixed and clinical studies are limited. As discussed above, population studies do support the concept that high serum levels of $1 \alpha, 25(\mathrm{OH})_{2} \mathrm{D}_{3}$ and/or its precursor $25(\mathrm{OH}) \mathrm{D}_{3}$ are associated with lower risk of initial disease development and may retard progression. However, tissue uptake and cellular metabolism of these metabolites in vivo is likely to be highly relevant to cancer biology, yet few studies have successfully measured these parameters. In addition, there is little data on how systemic vitamin D status might interact with other known breast cancer risk factors including genetic (BRCA1, BRCA2, ATM), endocrine (estrogen, progesterone) and environmental (radiation, carcinogens) modulators of breast cancer development. Genomic profiling has characterized many $1 \alpha, 25(\mathrm{OH})_{2} \mathrm{D}_{3}$ responsive targets in normal mammary cells and in breast cancers providing valuable insight into the molecular actions of $1 \alpha, 25(\mathrm{OH})_{2} \mathrm{D}_{3}$ and the VDR in regulation of cell cycle, apoptosis and differentiation. New areas of emphasis suggested by recent studies include regulation of tumor metabolism and activation of innate immune responses. However, the role of VDR in individual cell types (ie epithelial, adipose, fibroblast, endothelial, immune) of normal and tumor tissues remains to be clarified. Furthermore, there has been limited attention directed at understanding how VDR integrates signaling between these diverse cell types and what soluble signals and paracrine pathways may be regulated by $1 \alpha, 25(\mathrm{OH})_{2} \mathrm{D}_{3}$ in the tissue and tumor microenvironment. Finally, the possible interactions of VDR with other nuclear receptors and their ligands (particularly RXR family) in control of mammary cell fate/carcinogenesis will require additional study.

\section{REFERENCES}

Abedin, S. A., Thorne, J. L., Battaglia, S., Maguire, O., Hornung, L. B., Doherty, A. P., et al. (2009). Elevated NCOR1 disrupts a network of dietary-sensing nuclear receptors in bladder cancer cells. Carcinogenesis 30, 449-456. doi: 10.1093/carcin/bgp005

Agadir, A., Lazzaro, G., Zheng, Y., Zhang, X. K., and Mehta, R. (1999). Resistance of HBL100 human breast epithelial cells to vitamin D action. Carcinogenesis 20, 577-582. doi: 10.1093/carcin/20.4.577

Albertson, D. G., Ylstra, B., Segraves, R., Collins, C., Dairkee, S. H., Kowbel, D., et al. (2000). Quantitative mapping of amplicon structure by array CGH identifies CYP24 as a candidate oncogene. Nat. Genet. 25, 144-146. doi: 10.1038/75985

Alvarez, J. A., Chowdhury, R., Jones, D. P., Martin, G. S., Brigham, K. L., Binongo, J. N., et al. (2014). Vitamin D status is independently associated with plasma glutathione and cysteine thiol/disulfide redox status in adults. Clin. Endocrinol. (Oxf.). doi: 10.1111/cen.12449. [Epub ahead of print].

Bauer, S. R., Hankinson, S. E., Bertone-Johnson, E. R., and Ding, E. L. (2013) Plasma vitamin D levels, menopause, and risk of breast cancer: dose-response meta-analysis of prospective studies. Medicine (Baltimore) 92, 123-131. doi: 10.1097/MD.0b013e3182943bc2

Berger, U., McClelland, R. A., Wilson, P., Greene, G. L., Haussler, M. R., Pike, J. W., et al. (1991). Immunocytochemical detection of estrogen receptor, progesterone receptor and 1,25-dihydroxyvitamin $\mathrm{D}_{3}$ receptor in breast cancer and relation to prognosis. Cancer Res. 51, 239-244.

Berger, U., Wilson, P., McClelland, R. A., Colston, K., Haussler, M. R., Pike, J. W., et al. (1987). Immunocytochemical detection of 1,25-dihydroxyvitamin D3 receptor in breast cancer. Cancer Res. 47, 6793-6799.

Bikle, D. D. (2012). Protective actions of vitamin D in UVB induced skin cancer. Photochem. Photobiol. Sci. 11, 1808-1816. doi: 10.1039/c2pp25251a

Bilinski, K., and Boyages, J. (2013). Association between 25-hydroxyvitamin D concentration and breast cancer risk in an Australian population: an observational case-control study. Breast Cancer Res. Treat. 137, 599-607. doi: 10.1007/s10549012-2381-1

Bolland, M. J., Grey, A., Gamble, G. D., and Reid, I. R. (2011). Calcium and vitamin D supplements and health outcomes: a reanalysis of the Women's Health Initiative (WHI) limited-access data set. Am. J. Clin. Nutr. 94, 1144-1149. doi: 10.3945/ajcn.111.015032 
Bruce, D., Yu, S., Ooi, J. H., and Cantorna, M. T. (2011). Converging pathways lead to overproduction of IL-17 in the absence of vitamin D signaling. Int. Immunol. 23, 519-528. doi: 10.1093/intimm/dxr045

Buras, R. R., Schumaker, L. M., Davoodi, F., Brenner, R. V., Shabahang, M., Nauta, R. J., et al. (1994). Vitamin D receptors in breast cancer cells. Breast Cancer Res. Treat. 31, 191-202. doi: 10.1007/BF00666153

Byrne, I., Flanagan, L., Tenniswood, M., and Welsh, J. E. (2000). Identification of a hormone responsive promoter immediately upstream of exon 1c in the human vitamin D receptor gene. Endocrinology 141, 2829-2836. doi: 10.1210/en.141.8.2829

Caan, B. J., Sweeney, C., Habel, L. A., Kwan, M., Kroenke, C. H., Weltzien, E., et al. (2014). Intrinsic subtypes from the PAM50 gene expression assay in a population-based breast cancer survivor cohort: prognostication of short and long term outcomes. Cancer Epidemiol. Biomarkers Prev. 23, 714-724. doi: 10.1158/1055-9965.EPI-13-1017

Campos, L. T., Brentani, H., Roela, R. A., Katayama, M. L., Lima, L., Rolim, C. F., et al. (2013). Differences in transcriptional effects of 1alpha, 25 dihydroxyvitamin D3 on fibroblasts associated to breast carcinomas and from paired normal breast tissues. J. Steroid Biochem. Mol. Biol. 133, 12-24. doi: 10.1016/j.jsbmb.2012.08.002

Cancer Genome Atlas Network. (2012). Comprehensive molecular portraits of human breast tumours. Nature 490, 61-70. doi: 10.1038/nature11412

Cauley, J. A., Chlebowski, R. T., Wactawski-Wende, J., Robbins, J. A., Rodabough, R. J., Chen, Z., et al. (2013). Calcium plus vitamin D supplementation and health outcomes five years after active intervention ended: the Women's Health Initiative. J. Womens Health (Larchmt) 22, 915-929. doi: 10.1089/jwh.2013.4270

Ching, S., Kashinkunti, S., Niehaus, M. D., and Zinser, G. M. (2011). Mammary adipocytes bioactivate 25-hydroxyvitamin $\mathrm{D}(3)$ and signal via vitamin $\mathrm{D}(3)$ receptor, modulating mammary epithelial cell growth. J. Cell. Biochem. 112, 3393-3405. doi: $10.1002 /$ jcb.23273

Colston, K., Wilkinson, J. R., and Coombes, R. C. (1986). 1,25-Dihydroxyvitamin D3 binding in estrogen responsive rat breast tumor. Endocrinology 119, 397-403. doi: 10.1210/endo-119-1-397

Cordes, T., Diesing, D., Becker, S., Fischer, D., Diedrich, K., and Friedrich, M. (2007). Expression of splice variants of 1alpha-hydroxylase in MCF7 breast cancer cells. J. Steroid Biochem. Mol. Biol. 103, 326-329. doi: 10.1016/j.jsbmb.2006.12.034

de Lyra, E. C., da Silva, I. A., Katayama, M. L., Brentani, M. M., Nonogaki, S., Goes, J. C., et al. (2006). 25(OH)D3 and $1,25(\mathrm{OH})_{2} \mathrm{D}_{3}$ serum concentration and breast tissue expression of 1alpha-hydroxylase, 24-hydroxylase and Vitamin D receptor in women with and without breast cancer. J. Steroid Biochem. Mol. Biol. 100, 184-192. doi: 10.1016/j.jsbmb.2006.04.009

Devitt, A., Parker, K. G., Ogden, C. A., Oldreive, C., Clay, M. F., Melville, L. A., et al. (2004). Persistence of apoptotic cells without autoimmune disease or inflammation in CD14 ${ }^{-/-}$mice. J. Cell Biol. 167, 1161-1170. doi: 10.1083/jcb. 200410057

Dogan, M., Cesur, Y., Zehra Dogan, S., Kaba, S., Bulan, K., and Cemek, M. (2012). Oxidant/antioxidant system markers and trace element levels in children with nutritional rickets. J. Pediatr. Endocrinol. Metab. 25, 1129-1139. doi: 10.1515/jpem-2012-0153

Edvardsen, K., Veierod, M. B., Brustad, M., Braaten, T., Engelsen, O., and Lund, E. (2011). Vitamin D-effective solar UV radiation, dietary vitamin D and breast cancer risk. Int. J. Cancer 128, 1425-1433. doi: 10.1002/ijc.25463

El Abdaimi, K., Dion, N., Papavasiliou, V., Cardinal, P. E., Binderup, L., Goltzman, D., et al. (2000). The vitamin D analogue EB1089 prevents skeletal metastasis and prolongs survival time in nude mice transplanted with human breast cancer cells. Cancer Res. 60, 4412-4418.

Engel, L. S., Satagopan, J., Sima, C. S., Orlow, I., Mujumdar, U., Coble, J., et al. (2014). Sun exposure, vitamin d receptor genetic variants, and risk of breast cancer in the agricultural health study. Environ. Health Perspect. 122, 165-171. doi: 10.1289/ehp.1206274

Engel, P., Fagherazzi, G., Mesrine, S., Boutron-Ruault, M. C., and Clavel-Chapelon, F. (2011). Joint effects of dietary vitamin D and sun exposure on breast cancer risk: results from the French E3N cohort. Cancer Epidemiol. Biomarkers Prev. 20, 187-198. doi: 10.1158/1055-9965.EPI-10-1039

Escaleira, M. T., and Brentani, M. M. (1999). Vitamin D3 receptor (VDR) expression in HC-11 mammary cells: regulation by growth-modulatory agents, differentiation, and Ha-ras transformation. Breast Cancer Res. Treat. 54, 123-133. doi: 10.1023/A:1006198107805
Fischer, D., Seifert, M., Becker, S., Ludders, D., Cordes, T., Reichrath, J., et al. (2007). 25-Hydroxyvitamin D3 lalpha-hydroxylase splice variants in breast cell lines MCF-7 and MCF-10. Cancer Genomics Proteomics 4, 295-300.

Flanagan, L., Packman, K., Juba, B., O’Neill, S., Tenniswood, M., and Welsh, J. (2003). Efficacy of Vitamin D compounds to modulate estrogen receptor negative breast cancer growth and invasion. J. Steroid Biochem. Mol. Biol. 84, 181-192. doi: 10.1016/S0960-0760(03)00028-1

Gilad, L. A., Tirosh, O., and Schwartz, B. (2006). Phytoestrogens regulate transcription and translation of vitamin D receptor in colon cancer cells. J. Endocrinol. 191, 387-398. doi: 10.1677/joe.1.06930

Gordon-Thomson, C., Gupta, R., Tongkao-On, W., Ryan, A., Halliday, G. M., and Mason, R. S. (2012). lalpha,25 dihydroxyvitamin D3 enhances cellular defences against UV-induced oxidative and other forms of DNA damage in skin. Photochem. Photobiol. Sci. 11, 1837-1847. doi: 10.1039/c2pp25202c

Grant, W. B. (2013). Update on evidence that support a role of solar ultraviolet-B irradiance in reducing cancer risk. Anticancer Agents Med. Chem. 13, 140-146. doi: $10.2174 / 187152013804487425$

Grotsky, D. A., Gonzalez-Suarez, I., Novell, A., Neumann, M. A., Yaddanapudi, S. C., Croke, M., et al. (2013). BRCA1 loss activates cathepsin L-mediated degradation of 53BP1 in breast cancer cells. J. Cell Biol. 200, 187-202. doi: $10.1083 /$ jcb. 201204053

Heidenreich, S. (1999). Monocyte CD14: a multifunctional receptor engaged in apoptosis from both sides. J. Leukoc. Biol. 65, 737-743.

Hopkins, M. H., Owen, J., Ahearn, T., Fedirko, V., Flanders, W. D., Jones, D. P., et al. (2011). Effects of supplemental vitamin D and calcium on biomarkers of inflammation in colorectal adenoma patients: a randomized, controlled clinical trial. Cancer Prev. Res. (Phila.) 4, 1645-1654. doi: 10.1158/1940-6207.CAPR11-0105

Hussain, E. A., Mehta, R. R., Ray, R., Das Gupta, T. K., and Mehta, R. G. (2003). Efficacy and mechanism of action of 1alpha-hydroxy-24-ethyl-cholecalciferol (1alpha[OH]D5) in breast cancer prevention and therapy. Recent Results Cancer Res. 164, 393-411. doi: 10.1007/978-3-642-55580-0_29

Jacobson, E. A., James, K. A., Newmark, H. L., and Carroll, K. K. (1989). Effects of dietary fat, calcium, and vitamin $\mathrm{D}$ on growth and mammary tumorigenesis induced by 7,12-dimethylbenz(a)anthracene in female Sprague-Dawley rats. Cancer Res. 49, 6300-6303.

John, E. M., Schwartz, G. G., Dreon, D. M., and Koo, J. (1999). Vitamin D and breast cancer risk: the NHANES I Epidemiologic follow-up study, 1971-1975 to 1992. National Health and Nutrition Examination Survey. Cancer Epidemiol. Biomarkers Prev. 8, 399-406.

John, E. M., Schwartz, G. G., Koo, J., Wang, W., and Ingles, S. A. (2007). Sun exposure, vitamin $\mathrm{D}$ receptor gene polymorphisms, and breast cancer risk in a multiethnic population. Am. J. Epidemiol. 166, 1409-1419. doi: 10.1093/aje/kwm259

Kallay, E., Bareis, P., Bajna, E., Kriwanek, S., Bonner, E., Toyokuni, S., et al. (2002). Vitamin D receptor activity and prevention of colonic hyperproliferation and oxidative stress. Food Chem. Toxicol. 40, 1191-1196. doi: 10.1016/S02786915(02)00030-3

Kemmis, C. M., Salvador, S. M., Smith, K. M., and Welsh, J. (2006). Human mammary epithelial cells express CYP27B1 and are growth inhibited by 25hydroxyvitamin D-3, the major circulating form of vitamin D-3. J. Nutr. 136, 887-892.

Kemmis, C. M., and Welsh, J. (2008). Mammary epithelial cell transformation is associated with deregulation of the vitamin D pathway. J. Cell. Biochem. 105, 980-988. doi: 10.1002/jcb.21896

Kim, H. J., Lee, Y. M., Ko, B. S., Lee, J. W., Yu, J. H., Son, B. H., et al. (2011). Vitamin D deficiency is correlated with poor outcomes in patients with luminal-type breast cancer. Ann. Surg. Oncol. 18, 1830-1836. doi: 10.1245/s10434-010-1465-6

Kim, Y., Franke, A. A., Shvetsov, Y. B., Wilkens, L. R., Cooney, R. V., Lurie, G., et al. (2014). Plasma 25-hydroxyvitamin D3 is associated with decreased risk of postmenopausal breast cancer in whites: a nested case-control study in the multiethnic cohort study. BMC Cancer 14:29. doi: 10.1186/1471-2407-14-29

Knower, K. C., Chand, A. L., Eriksson, N., Takagi, K., Miki, Y., Sasano, H., et al. (2013). Distinct nuclear receptor expression in stroma adjacent to breast tumors. Breast Cancer Res. Treat. 142, 211-223. doi: 10.1007/s10549-013-2716-6

Krishnan, A. V., and Feldman, D. (2011). Mechanisms of the anti-cancer and antiinflammatory actions of vitamin D. Annu. Rev. Pharmacol. Toxicol. 51, 311-336. doi: 10.1146/annurev-pharmtox-010510-100611

Kuhn, T., Kaaks, R., Becker, S., Eomois, P. P., Clavel-Chapelon, F., Kvaskoff, M., et al. (2013). Plasma 25-hydroxyvitamin D and the risk of breast cancer in 
the European prospective investigation into cancer and nutrition: a nested case-control study. Int. J. Cancer 133, 1689-1700. doi: 10.1002/ijc.28172

Laporta, E., and Welsh, J. (2013). Modeling vitamin D actions in triplenegative/basal-like breast cancer. J. Steroid Biochem. Mol. Biol. doi: 10.1016/j.jsbmb.2013.10.022. [Epub ahead of print].

Larriba, M. J., Bonilla, F., and Munoz, A. (2010). The transcription factors Snaill and Snail2 repress vitamin D receptor during colon cancer progression. J. Steroid Biochem. Mol. Biol. 121, 106-109. doi: 10.1016/j.jsbmb.2010. 01.014

Lee, H. J., Liu, H., Goodman, C., Ji, Y., Maehr, H., Uskokovic, M., et al. (2006). Gene expression profiling changes induced by a novel Gemini Vitamin D derivative during the progression of breast cancer. Biochem. Pharmacol. 72, 332-343. doi: 10.1016/j.bcp.2006.04.030

Lee, J. W., Paape, M. J., Elsasser, T. H., and Zhao, X. (2003). Recombinant soluble CD14 reduces severity of intramammary infection by Escherichia coli. Infect. Immun. 71, 4034-4039. doi: 10.1128/IAI.71.7.4034-4039.2003

Lin, J., Manson, J. E., Lee, I. M., Cook, N. R., Buring, J. E., and Zhang, S. M. (2007). Intakes of calcium and vitamin $\mathrm{D}$ and breast cancer risk in women. Arch. Intern. Med. 167, 1050-1059. doi: 10.1001/archinte.167.10.1050

Lopes, N., Paredes, J., Costa, J. L., Ylstra, B., and Schmitt, F. (2012). Vitamin D and the mammary gland: a review on its role in normal development and breast cancer. Breast Cancer Res. 14:211. doi: 10.1186/bcr3178

Lopes, N., Sousa, B., Martins, D., Gomes, M., Vieira, D., Veronese, L. A., et al. (2010). Alterations in Vitamin D signalling and metabolic pathways in breast cancer progression: a study of VDR, CYP27B1 and CYP24A1 expression in benign and malignant breast lesions. BMC Cancer 10:483. doi: 10.1186/14712407-10-483

Maalmi, H., Ordonez-Mena, J. M., Schottker, B., and Brenner, H. (2014). Serum 25hydroxyvitamin D levels and survival in colorectal and breast cancer patients: systematic review and meta-analysis of prospective cohort studies. Eur. J. Cancer 50, 1510-1521. doi: 10.1016/j.ejca.2014.02.006

Malinen, M., Saramaki, A., Ropponen, A., Degenhardt, T., Vaisanen, S., and Carlberg, C. (2008). Distinct HDACs regulate the transcriptional response of human cyclin-dependent kinase inhibitor genes to Trichostatin A and 1alpha,25-dihydroxyvitamin D3. Nucleic Acids Res. 36, 121-132. doi: 10.1093/nar/gkm913

McCarthy, K., Laban, C., Bustin, S. A., Ogunkolade, W., Khalaf, S., Carpenter, R., et al. (2009). Expression of 25-hydroxyvitamin D-1-alpha-hydroxylase, and vitamin $\mathrm{D}$ receptor mRNA in normal and malignant breast tissue. Anticancer Res. 29, 155-157.

McMahon, L., Schwartz, K., Yilmaz, O., Brown, E., Ryan, L. K., and Diamond, G. (2011). Vitamin D-mediated induction of innate immunity in gingival epithelial cells. Infect. Immun. 79, 2250-2256. doi: 10.1128/IAI 00099-11

Mehta, R. G., Moriarty, R. M., Mehta, R. R., Penmasta, R., Lazzaro, G., Constantinou, A., et al. (1997). Prevention of preneoplastic mammary lesion development by a novel vitamin D analogue, lalpha-hydroxyvitamin D5. J. Natl. Cancer Inst. 89, 212-218. doi: 10.1093/jnci/89.3.212

Milani, C., Katayama, M. L., de Lyra, E. C., Welsh, J., Campos, L. T., Brentani, M. M., et al. (2013). Transcriptional effects of 1,25 dihydroxyvitamin D(3) physiological and supra-physiological concentrations in breast cancer organotypic culture. BMC Cancer 13:119. doi: 10.1186/1471-2407-13-119

Mittal, M. K., Myers, J. N., Misra, S., Bailey, C. K., and Chaudhuri, G. (2008). In vivo binding to and functional repression of the VDR gene promoter by SLUG in human breast cells. Biochem. Biophys. Res. Commun. 372, 30-34. doi: 10.1016/j.bbrc.2008.04.187

Mohr, S. B., Gorham, E. D., Kim, J., Hofflich, H., and Garland, C. F. (2014). Metaanalysis of Vitamin D sufficiency for improving survival of patients with breast cancer. Anticancer Res. 34, 1163-1166.

Nakai, K., Fujii, H., Kono, K., Goto, S., Kitazawa, R., Kitazawa, S., et al. (2014). Vitamin D activates the nrf2-keapl antioxidant pathway and ameliorates nephropathy in diabetic rats. Am. J. Hypertens. 27, 586-595. doi: 10.1093/ajh/hpt160

Narvaez, C. J., Simmons, K. M., Brunton, J., Salinero, A., Chittur, S. V., and Welsh, J. E. (2013). Induction of STEAP4 correlates with 1,25-dihydroxyvitamin D3 stimulation of adipogenesis in mesenchymal progenitor cells derived from human adipose tissue. J. Cell. Physiol. 228, 2024-2036. doi: 10.1002/jcp.24371

Nolan, E., Donepudi, M., VanWeelden, K., Flanagan, L., and Welsh, J. E. (1998). Dissociation of vitamin D3 and anti-estrogen mediated growth regulation in
MCF-7 breast cancer cells. Mol. Cell. Biochem. 188, 13-20. doi: 10.1007/978-14615-5763-0_2

Ooi, L. L., Zhou, H., Kalak, R., Zheng, Y., Conigrave, A. D., Seibel, M. J., et al. (2010). Vitamin D deficiency promotes human breast cancer growth in a murine model of bone metastasis. Cancer Res. 70, 1835-1844. doi: 10.1158/0008-5472.CAN-09-3194

Peng, X., Hawthorne, M., Vaishnav, A., St-Arnaud, R., and Mehta, R. G. (2009) 25-Hydroxyvitamin D3 is a natural chemopreventive agent against carcinogen induced precancerous lesions in mouse mammary gland organ culture. Breast Cancer Res. Treat. 113, 31-41. doi: 10.1007/s10549-008-9900-0

Peng, X., Vaishnav, A., Murillo, G., Alimirah, F., Torres, K. E., and Mehta, R. G. (2010). Protection against cellular stress by 25 -hydroxyvitamin D3 in breast epithelial cells. J. Cell. Biochem. 110, 1324-1333. doi: 10.1002/jcb.22646

Peppone, L. J., Rickles, A. S., Janelsins, M. C., Insalaco, M. R., and Skinner, K. A. (2012). The association between breast cancer prognostic indicators and serum 25-OH vitamin D levels. Ann. Surg. Oncol. 19, 2590-2599. doi: 10.1245/s10434012-2297-3

Rainville, C., Khan, Y., and Tisman, G. (2009). Triple negative breast cancer patients presenting with low serum vitamin D levels: a case series. Cases J. 2:8390. doi: $10.4076 / 1757-1626-2-8390$

Redaniel, M. T., Gardner, M. P., Martin, R. M., and Jeffreys, M. (2014). The association of vitamin D supplementation with the risk of cancer in postmenopausal women. Cancer Causes Control 25, 267-271. doi: 10.1007/s10552-013-0328-4

Rose, A. A., Elser, C., Ennis, M., and Goodwin, P. J. (2013). Blood levels of vitamin $\mathrm{D}$ and early stage breast cancer prognosis: a systematic review and meta-analysis. Breast Cancer Res. Treat. 141, 331-339. doi: 10.1007/s10549-013-2713-9

Rowling, M. J., Kemmis, C. M., Taffany, D. A., and Welsh, J. (2006). Megalinmediated endocytosis of vitamin D binding protein correlates with 25hydroxycholecalciferol actions in human mammary cells. J. Nutr. 136, 2754-2759.

Santagata, S., Thakkar, A., Ergonul, A., Wang, B., Woo, T., Hu, R., et al. (2014) Taxonomy of breast cancer based on normal cell phenotype predicts outcome. J. Clin. Invest. 124, 859-870. doi: 10.1172/JCI70941

Scheible, C., Thill, M., Baum, S., Solomayer, E., and Friedrich, M. (2014) Implication of CYP24A1 splicing in breast cancer. Anticancer Agents Med. Chem. 14, 109-114. doi: 10.2174/18715206113139990311

Segersten, U., Holm, P. K., Bjorklund, P., Hessman, O., Nordgren, H., Binderup, L., et al. (2005). 25-Hydroxyvitamin D3 lalpha-hydroxylase expression in breast cancer and use of non-1alpha-hydroxylated vitamin D analogue. Breast Cancer Res. 7, R980-R986. doi: 10.1186/bcr1332

Simpson, E. R., and Brown, K. A. (2013). Minireview: obesity and breast cancer: a tale of inflammation and dysregulated metabolism. Mol. Endocrinol. 27, 715-725. doi: 10.1210/me.2013-1011

Sperati, F., Vici, P., Maugeri-Sacca, M., Stranges, S., Santesso, N., Mariani, L., et al. (2013). Vitamin D supplementation and breast cancer prevention: a systematic review and meta-analysis of randomized clinical trials. PLoS ONE 8:e69269. doi: 10.1371/journal.pone.0069269

Stein, T., Morris, J. S., Davies, C. R., Weber-Hall, S. J., Duffy, M. A., Heath, V. J., et al. (2004). Involution of the mouse mammary gland is associated with an immune cascade and an acute-phase response, involving LBP, CD14 and STAT3. Breast Cancer Res. 6, R75-R91. doi: 10.1186/bcr753

Suetani, R. J., Ho, K., Jindal, S., Manavis, J., Neilsen, P. M., Pishas, K. I., et al. (2012). A comparison of vitamin D activity in paired non-malignant and malignant human breast tissues. Mol. Cell. Endocrinol. 362, 202-210. doi: 10.1016/j.mce.2012.06.022

Sun, J., Zhong, W., Gu, Y., Groome, L. J., and Wang, Y. (2014). 1,25(OH ${ }_{2} \mathrm{D}_{3}$ suppresses COX-2 up-regulation and thromboxane production in placental trophoblast cells in response to hypoxic stimulation. Placenta 35, 143-145. doi: 10.1016/j.placenta.2013.12.002

Swami, S., Krishnan, A. V., Wang, J. Y., Jensen, K., Horst, R., Albertelli, M. A. et al. (2012). Dietary vitamin $\mathrm{D}(3)$ and 1,25-dihydroxyvitamin $\mathrm{D}(3)$ (calcitriol) exhibit equivalent anticancer activity in mouse xenograft models of breast and prostate cancer. Endocrinology 153, 2576-2587. doi: 10.1210/en.2011-1600

Swami, S., Raghavachari, N., Muller, U. R., Bao, Y. P., and Feldman, D. (2003). Vitamin D growth inhibition of breast cancer cells: gene expression patterns assessed by cDNA microarray. Breast Cancer Res. Treat. 80, 49-62. doi: 10.1023/A:1024487118457

Tennant, I., Pound, J. D., Marr, L. A., Willems, J. J., Petrova, S., Ford, C. A., et al. (2013). Innate recognition of apoptotic cells: novel apoptotic cell-associated 
molecular patterns revealed by crossreactivity of anti-LPS antibodies. Cell Death Differ. 20, 698-708. doi: 10.1038/cdd.2012.165

Ting, H. J., Yasmin-Karim, S., Yan, S. J., Hsu, J. W., Lin, T. H., Zeng, W., et al. (2012). A positive feedback signaling loop between ATM and the vitamin D receptor is critical for cancer chemoprevention by vitamin D. Cancer Res. 72, 958-968. doi: 10.1158/0008-5472.CAN-11-0042

Townsend, K., Banwell, C. M., Guy, M., Colston, K. W., Mansi, J. L., Stewart, P. M., et al. (2005). Autocrine metabolism of vitamin D in normal and malignant breast tissue. Clin. Cancer Res. 11, 3579-3586. doi: 10.1158/1078-0432.CCR-042359

Uberti, F., Lattuada, D., Morsanuto, V., Nava, U., Bolis, G., Vacca, G., et al. (2014). Vitamin D protects Human Endothelial Cells from oxidative stress through the autophagic and survival pathways. J. Clin. Endocrinol. Metab. 99, 1367-1374. doi: 10.1210/jc.2013-2103

Valrance, M. E., Brunet, A. H., and Welsh, J. (2007). Vitamin D receptordependent inhibition of mammary tumor growth by EB1089 and ultraviolet radiation in vivo. Endocrinology 148, 4887-4894. doi: 10.1210/en. 2007-0267

van der Rhee, H., Coebergh, J. W., and de Vries, E. (2013). Is prevention of cancer by sun exposure more than just the effect of vitamin D? A systematic review of epidemiological studies. Eur. J. Cancer 49, 1422-1436. doi 10.1016/j.ejca.2012.11.001

Vidal, K., and Donnet-Hughes, A. (2008). CD14: a soluble pattern recognition receptor in milk. Adv. Exp. Med. Biol. 606, 195-216. doi: 10.1007/978-0-38774087-4_7

Wall, R., Powell, A., Sohn, E., Foster-Frey, J., Bannerman, D., and Paape, M. (2009). Enhanced host immune recognition of mastitis causing Escherichia coli in CD-14 transgenic mice. Anim. Biotechnol. 20, 1-14. doi: 10.1080/10495390802594206

Wang, D., Velez de-la-Paz, O. I., Zhai, J. X., and Liu, D. W. (2013). Serum 25hydroxyvitamin $\mathrm{D}$ and breast cancer risk: a meta-analysis of prospective studies. Tumour Biol. 34, 3509-3517. doi: 10.1007/s13277-013-0929-2

Warburg, O. (1956). On the origin of cancer cells. Science 123, 309-314. doi: 10.1126/science.123.3191.309

Welsh, J. (2012). Cellular and molecular effects of vitamin D on carcinogenesis. Arch. Biochem. Biophys. 523, 107-114. doi: 10.1016/j.abb.2011.10.019

Welsh, J., Zinser, L. N., Mianecki-Morton, L., Martin, J., Waltz, S. E., James, H., et al. (2011). Age-related changes in the epithelial and stromal compartments of the mammary gland in normocalcemic mice lacking the vitamin D3 receptor. PLoS ONE 6:e16479. doi: 10.1371/journal.pone.0016479

Wietzke, J. A., and Welsh, J. (2003). Phytoestrogen regulation of a Vitamin D3 receptor promoter and 1,25-dihydroxyvitamin D3 actions in human breast cancer cells. J. Steroid Biochem. Mol. Biol. 84, 149-157. doi: 10.1016/S09600760(03)00024-4
Willnow, T. E., and Nykjaer, A. (2002). Pathways for kidney-specific uptake of the steroid hormone 25-hydroxyvitamin D3. Curr. Opin. Lipidol. 13, 255-260. doi: 10.1097/00041433-200206000-00004

Yao, S., and Ambrosone, C. B. (2013). Associations between vitamin D deficiency and risk of aggressive breast cancer in African-American women. J. Steroid Biochem. Mol. Biol. 136, 337-341. doi: 10.1016/j.jsbmb.2012.09.010

Zheng, J., Watson, A. D., and Kerr, D. E. (2006). Genome-wide expression analysis of lipopolysaccharide-induced mastitis in a mouse model. Infect. Immun. 74, 1907-1915. doi: 10.1128/IAI.74.3.1907-1915.2006

Zheng, W., Tayyari, F., Gowda, G. A., Raftery, D., McLamore, E. S., Shi, J., et al. (2013). 1,25-dihydroxyvitamin D regulation of glucose metabolism in Harveyras transformed MCF10A human breast epithelial cells. J. Steroid Biochem. Mol. Biol. 138, 81-89. doi: 10.1016/j.jsbmb.2013.03.012

Zhong, W., Gu, B., Gu, Y., Groome, L. J., Sun, J., and Wang, Y. (2014). Activation of vitamin D receptor promotes VEGF and CuZn-SOD expression in endothelial cells. J. Steroid Biochem. Mol. Biol. 140, 56-62. doi: 10.1016/j.jsbmb.2013.11.017

Zinser, G., Packman, K., and Welsh, J. (2002). Vitamin D(3) receptor ablation alters mammary gland morphogenesis. Development 129, 3067-3076.

Zinser, G. M., McEleney, K., and Welsh, J. (2003). Characterization of mammary tumor cell lines from wild type and vitamin $\mathrm{D}(3)$ receptor knockout mice. Mol. Cell. Endocrinol. 200, 67-80. doi: 10.1016/S0303-7207(02)00416-1

Zinser, G. M., and Welsh, J. (2004a). Accelerated mammary gland development during pregnancy and delayed postlactational involution in vitamin $\mathrm{D} 3$ receptor null mice. Mol. Endocrinol. 18, 2208-2223. doi: 10.1210/me.2003-0469

Zinser, G. M., and Welsh, J. (2004b). Vitamin D receptor status alters mammary gland morphology and tumorigenesis in MMTV-neu mice. Carcinogenesis 25, 2361-2372. doi: 10.1093/carcin/bgh271

Conflict of Interest Statement: The authors declare that the research was conducted in the absence of any commercial or financial relationships that could be construed as a potential conflict of interest.

Received: 08 April 2014; accepted: 17 May 2014; published online: 13 June 2014. Citation: Narvaez CJ, Matthews D, LaPorta E, Simmons KM, Beaudin S and Welsh $J$ (2014) The impact of vitamin D in breast cancer: genomics, pathways, metabolism. Front. Physiol. 5:213. doi: 10.3389/fphys.2014.00213

This article was submitted to Integrative Physiology, a section of the journal Frontiers in Physiology.

Copyright () 2014 Narvaez, Matthews, LaPorta, Simmons, Beaudin and Welsh. This is an open-access article distributed under the terms of the Creative Commons Attribution License (CC BY). The use, distribution or reproduction in other forums is permitted, provided the original author (s) or licensor are credited and that the original publication in this journal is cited, in accordance with accepted academic practice. No use, distribution or reproduction is permitted which does not comply with these terms. 